\title{
Comparing biodiversity effects among ecosystem engineers of contrasting strength: macrofauna diversity in Zostera noltii and Spartina anglica vegetations
}

\author{
Tjeerd J. Bouma $\cdot$ Victor Ortells $\cdot$ Tom Ysebaert
}

Received: 4 October 2007/Revised: 25 April 2008/Accepted: 27 April 2008/Published online: 19 December 2008

(C) The Author(s) 2008. This article is published with open access at Springerlink.com

\begin{abstract}
Whereas it is well known that ecosystem engineers can have a large influence on biodiversity, underlying mechanisms are still not fully clear. We try to enhance insight by comparing biodiversity effects of two neighboring intertidal, clonal, ecosystem engineering plant species that modify the physical environmental parameters in a similar way, but with a different magnitude. Macrobenthic assemblages were compared between meadows of the seagrass Zostera noltii, small patches $(\leq 0.5 \mathrm{~m} \emptyset)$ and large areas $(\gg 5 \mathrm{~m} \emptyset)$ of the emergent halophyte Spartina anglica and the surrounding bare tidal mudflat (control). Multivariate analyses revealed that the mudflat benthic assemblage and Zostera meadow assemblage showed highest similarities, whereas the Spartina marsh assemblage showed the highest dissimilarity with these two areas. Whereas the descriptive nature of our study limits interpretation of the data, some clear patterns were observed. For all vegetated areas, species diversity was lower compared to the unvegetated mudflat, and we observed a strong shift from endo- towards epibenthic species, suggesting that increased above-ground habitat complexity may be a main driving process in our system. As there were no clear patterns related to feeding types, food availability/productivity appeared to be of minor importance in structuring the benthic assemblages. Nevertheless, animals were in general smaller in vegetated areas. Patchiness had a distinct positive effect on biodiversity.
\end{abstract}

Communicated by K. Reise.

T. J. Bouma $(\bowtie) \cdot$ V. Ortells · T. Ysebaert Centre for Estuarine and Marine Ecology,

Netherlands Institute of Ecology (NIOO-KNAW),

Yerseke, The Netherlands

e-mail: t.bouma@nioo.knaw.nl
Keywords Ecosystem engineering - Zostera noltii . Spartina anglica $\cdot$ Benthic macrofauna $\cdot$ Plant-benthos interaction - Intertidal flats · Habitat modification · Invasion · Habitat complexity · Productivity $\cdot$ Diversity

\section{Introduction}

Since the introduction of the concept of ecosystem engineers as organisms that cause a large and/or distinct modification of the abiotic environment (Jones et al. 1994, 1997), it has been well recognized that ecosystem engineers can have a large influence on biodiversity within a specific habitat (e.g., see Crooks 2002; Wright and Jones 2004, 2006). For example, ecosystem engineers may enhance diversity by facilitating the presence of other organisms or communities (e.g., Bruno et al. 2003) which may eventually lead to succession (e.g., Castellanos et al. 1994; Fogel et al. 2004). Engineering species may also enhance diversity by causing spatial or temporal heterogeneity (e.g., excavations by pocket gophers, Reichman and Seabloom 2002; fungusgrowing termites, Jouquet et al. 2004). On the other hand, the physical alteration of ecosystems by invasive ecosystem engineers can have cascading effects on many resident species (Crooks 2002). Despite the well-recognized importance of ecosystem engineering for biodiversity, we lack fundamental understanding of how ecosystem engineers affect biodiversity and we are not yet able to predict the type of ecosystems in which engineers are most critical for biodiversity (Jones et al. 1997). Some broad generalizations can, however, be made in terms of ecosystem engineering effects on biodiversity via habitat complexity, productivity and spatial scale.

Engineers that increase habitat complexity tend to increase the diversity and/or the abundance of organisms 
(Crooks 2002). This is often the case for autogenic engineers that modify the habitat via their own physical structure (e.g., trees in a forest). Allogenic engineers that modify the environment by transforming living or non living materials from one state to another (e.g., beavers), often reduce habitat complexity and thereby biodiversity (Crooks 2002). Wright and Jones (2004) proposed that the diversity effect of an ecosystem engineer depend on the relationship between biodiversity and productivity. Ecosystems where biodiversity is restricted by a too low productivity would increase in diversity if the engineer enhances productivity, and vice versa. Similarly, ecosystems where biodiversity is restricted by a too high productivity would increase in diversity if the engineer reduces productivity, and vice versa (Wright and Jones 2004). In addition to effects on diversity by ecosystem engineers via modification of the habitat complexity and/or productivity, diversity effects also depend on spatial scale. At larger scales, the effects are commonly positive when comparing engineered and un-engineered environments (Jones et al. 1997; Wright and Jones 2004).

One of the main challenges in obtaining in depth understanding of the effects of ecosystem engineering on biodiversity is to detangle the effects due to a changed productivity versus due to a changed habitat complexity. A possible way to achieve this might be the comparison of effects on biodiversity by ecosystem engineers that modify the physical environmental parameters in a similar way, but differ in the magnitude that they modify the environment. In this study, we apply this approach by comparing the diversity effect of two well known neighboring ecosystem engineering clonal plant species that inhabit the intertidal transition zone between the bare tidal mudflat and the vegetated salt marsh: the seagrass Zostera noltii and the emergent halophyte Spartina anglica. Apart from their contrasting ecosystem engineering strength, this species selection is relevant because Spartina species invade tidal flats in many places in the world, thereby taking over bare mudflat as well as Zostera habitats (Lacambra et al. 2004; Wang et al. 2006; Cottet et al. 2007). Because of the latter, there is considerable concern about the impact of Spartina on benthic macrofauna and thereby birds that feed on these animals. Apart from a shift in benthic assemblages, birds may also not able to physically reach benthos living in the marsh vegetation. Researchers studying invasive Spartina have reported altered faunal composition and abundance (e.g., Hedge and Kriwoken 2000; Neira et al. 2005) and trophic function (Levin et al. 2006).

The seagrass $Z$. noltii and the emergent halophyte $S$. anglica differ in the extent that they modify their environment. Both species strongly enhance the habitat complexity by making shoots that protrude as physical structures on the mudflat. The vegetation of $Z$. noltii is most dense (Bouma et al. 2005), with the flexible shoots lying on the sediment surface at low tide. Spartina anglica is characterized by much taller and stiffer shoots and a larger above-ground biomass. Positive habitat complexity effects of Spartina on benthic assemblages may be counteracted by its effect on sediment properties, as Spartina forms well-defined dome-shaped tussocks (Castellanos et al. 1994; Bouma et al. 2007; van Hulzen et al. 2007) with a relatively compact, densely rooted, well aerated, dry sediment (Van Wesenbeeck et al. 2007). This effect on sediment properties may be expected to be more pronounced in mature Spartina marshes than in more recently established Spartina tussocks, as the latter will contain a lower shoot and root density.

Both Zostera and Spartina have been shown to enhance particle and sediment accretion by reduction of hydrodynamic energy in a complex way (for seagrasses see, e.g., Orth 1992; Bologna and Heck 2002; Widdows and Brinsley 2002; Blanchet et al. 2004; for Spartina see, e.g., Kneib 1984; Netto and Lana 1997; Widdows and Brinsley 2002). As the shoots of $S$. anglica are much stiffer and taller than the flexible shoots of Z. noltii, Spartina causes a much stronger attenuation of wave energy than Zostera (Bouma et al. 2005). Such reduction of hydrodynamic energy may lead to an enhanced accretion of organic materials and thereby an enhanced food supply to benthic animals that live from deposited debris (e.g., surface deposit feeders, grazers). However, because of the lower density of the Spartina than Zostera vegetation, Spartina maintains a higher canopy flux under unidirectional flow (Peralta et al. 2008). Such flux through the canopy is needed both to provide food supply to benthic animals that live inside vegetations and depend on water refreshment for their food supply (e.g., filter feeders; Brun et al., this issue) and to provide materials to maintain high rates of accretion within the vegetated areas (Peralta et al. 2008).

Based on the hydrodynamic and sediment engineering properties of both plant species, we hypothesize that (1) Spartina vegetated sediments will have finer sediment grain size and a higher organic matter content, and a reduced microalgal chlorophyll $a$ biomass relative to the adjacent unvegetated tidal flat sediments, with Zostera vegetations taking an intermediate position, and (2) that these differences cause changes in the benthic macrofauna assemblage structure and functional groups. That is, we expect that $(2 \mathrm{a})$ enhanced accretion of organic matter in vegetations may benefit the occurrence and diversity of deposit feeders, and that $(2 \mathrm{~b})$ the reduced hydrodynamic energy in vegetations will reduce overall food supply to filter feeders and thereby their occurrence and diversity. Based on the habitat complexity engineering properties of both plant species we furthermore hypothesize that (3) both plant species will cause a shift from endobenthic to 
epibenthic macroinvertebrate species, as the vegetation provides habitat and protects the epibenthic animals from predation. Based on the sediment engineering properties of both species, we predict this shift to be most pronounced in the Spartina vegetation, because of sediment compaction and sediment aeration. Finally, we hypothesize that (4) smaller and generally younger patches of Spartina support a more diverse benthic macrofaunal assemblage compared to larger and generally more mature Spartina patches, due to a stronger change in the sedimentary environment in the latter.

We tried to evaluate our hypotheses by determining the epi- and endobenthic macrofaunal diversity (i.e., species composition, functional groups by feeding types, abundance, biomass) in the seagrass $Z$. noltii, the emergent macrophyte $S$. anglica and in the adjacent bare, unvegetated mudflat. We focused on macrofaunal assemblages because it represents an important trophic link between primary producers and higher consumers such as birds and fishes. We estimated the vegetation effects on habitat complexity by counting the shoot density and estimating above- and below-ground biomass. We estimated accretion of organic debris by looking at the organic carbon content and the mud content, as mud is trapped along with organic debris. Since the attenuation of hydrodynamic energy is a spatial explicit process (e.g., see Bouma et al. 2005, 2007), we assessed the importance of scale by comparing small Spartina tussocks $(\leq 0.5 \mathrm{~m} \varnothing)$ and large patches of Spartina marsh $(>5.0 \mathrm{~m})$.

\section{Materials and methods}

\section{Study area}

The study was conducted at the transition from the tidal flat to the salt marsh at Ritthem $\left(51^{\circ} 27 \mathrm{~N}, 03^{\circ} 39 \mathrm{E}\right)$ at the mouth of the Westerschelde estuary, in the south-west of the Netherlands (Fig. 1). Ritthem is an embayment marsh that is protected by an extensive breakwater that was built in 1965 in connection with the Sloehaven harbor development, close to the harbor of the city of Vlissingen (Dyer et al. 2002). Nearby Ritthem, the mean vertical tidal range is $3.8 \mathrm{~m}$ and salinity is about 29 (Ysebaert et al. 2003). The transition from the tidal flat to the salt marsh is dominated by two plant species that grow very close to each other: the emergent macrophyte $S$. anglica and the seagrass species $Z$. noltii. The transition zone from mudflat to salt marsh has a gentle slope and no cliff occurred at the study site.
Experimental design

Within the transition zone from bare to vegetated, four distinct sampling habitats were distinguished: (i) bare mudflat, (ii) Zostera meadow, (iii) Spartina marsh vegetation (i.e., large patches, $>5.0 \mathrm{~m} \varnothing$ ) and (iv) small Spartina tussocks (i.e., $\leq 0.5 \mathrm{~m} \emptyset$ ). In the first three habitats, five locations were selected to obtain a block design. At each location three replicate sample sites were randomly chosen (Fig. 1). Unfortunately, it was not possible to find small Spartina tussocks located in such way that they could match the block design. Hence, 15 small tussocks were selected randomly. Each of these small tussocks was used as a single sample, as sampling would often mean that the whole tussock was lost. Sampling took place in the period where both the plant biomass and macrofaunal biomass has reached a maximum (i.e., 14th September and 4th October 2004).

\section{Sampling}

At each sampling point a frame of $1 \mathrm{~m}^{2}$ was placed over the vegetation or on the sediment. In case of the small, recently established Spartina tussocks (i.e., $\leq 0.5 \mathrm{~m} \emptyset$ ), the whole tussock was sampled and regarded as the sampling surface. Within this area, the number of stems and all visible worm piles of the lugworm Arenicola marina were counted. Subsequently, all vegetation and large epibenthos (i.e., the ones that are visible on the surface) were collected. The epibenthos was stored in buffered formaldehyde (4\%). The top centimeter of the sediment was collected with a syringe $(\varnothing 10 \mathrm{~mm})$ for grain size analysis and chlorophyll analysis. For each analysis three samples were collected randomly, lumped and immediately stored cooled in the dark. A core with a diameter of $110 \mathrm{~mm}$ was pushed $300 \mathrm{~mm}$ deep into the sediment to sample benthos. The core samples were stored in plastic bags until washing at the laboratory.

In the laboratory, the vegetation collected in the $1 \mathrm{~m}^{2}$ frames was washed carefully to remove sediment and to collect any macrobenthos attached to the vegetation. The macrobenthos was added to the epibenthic sample collected in the field. For each location, twenty stems of $S$. anglica and Z. noltii were used to measure the total length of the stem, the height where leaves branch off and leaf length. The 20 measured stems were dried separately from the others stems. All vegetation samples were dried at $80^{\circ} \mathrm{C}$ for 2-4 days, and subsequently weighed. After washing the sediment sample over a $1 \mathrm{~mm}$ mesh sieve, the endobenthos samples were stored in buffered formaldehyde (4\%) for later analysis. 
Fig. 1 Schematic

representation of the benthos sampling at our field site. Top left position of the study site in the southwestern part of The Netherlands. Top right Ritthem salt marsh at the mouth of the Westerschelde estuary. Bottom figure study site with position of the different sampling points in each of the four habitats. For detailed information about the sampling design: see text. The aerial picture underneath the sampling points is from a different year, so that samples taken in the vegetation (indicated in red) may appear to fall outside of the vegetation (color in online)
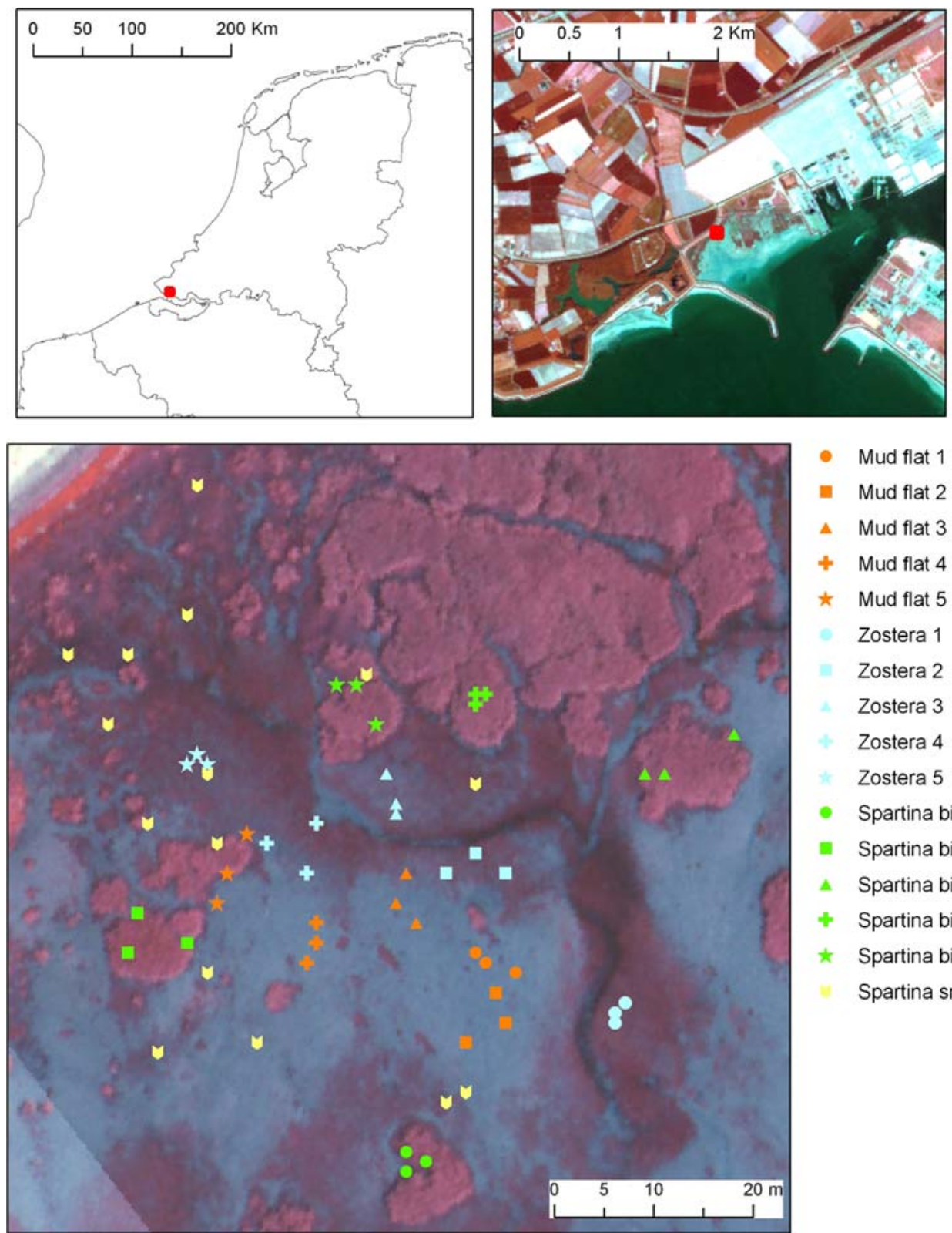

- Mud flat 1

aud flat 2

4. Mud flat 3

+ Mud flat 4

* Mud flat 5

Zostera 1

Zostera 2

Zostera 3

Zostera 4

Zostera 5

- Spartina big 1

n- Spartina big 2

4. Spartina big 3

+ Spartina big 4

* Spartina big 5

Spartina small
Analyzing epi- and endobenthos

Epifauna is defined as those animals that live on top of the sediment or are attached to structures above the sediment, and which spend most of their feeding activity on top of the benthic surface. Animals that spend most of their lives digging and burrowing in soft sediments are referred to as endofauna (infauna).

After staining the benthos with Rose Bengal, organisms were identified to species level (except for Nemertea, Oligochaeta, Chaetognata, Nudibranchia and Actinaria), counted and weighted. Since Annelids were often broken due to handling, only parts with a head structure were counted. The length of bivalves and some gastropods
(Macoma balthica, Cerastoderma edule, Mytilus edulis, Littorina littorea) and crustaceans (Carcinus maenas) were measured to the nearest $\mathrm{mm}$.

All species were grouped in taxonomic classes and functional groups based on the feeding type. We distinguished five functional groups (Table 1): (1) suspension feeders (SF) that filter water to collect their food, mainly phytoplankton (e.g., C. edule, Actiniaria); (2) surface deposit feeders (SDF) that typically feed on diatoms on the surface of the sediment (e.g., M. balthica, Tharyx marioni). This group also includes grazers that graze on microalgae on the sediment surface or vegetation (e.g., Hydrobia ulvae); (3) sub-surface deposit feeders (SSDF) that predominantly feed on micro-organisms, phytobenthos and 


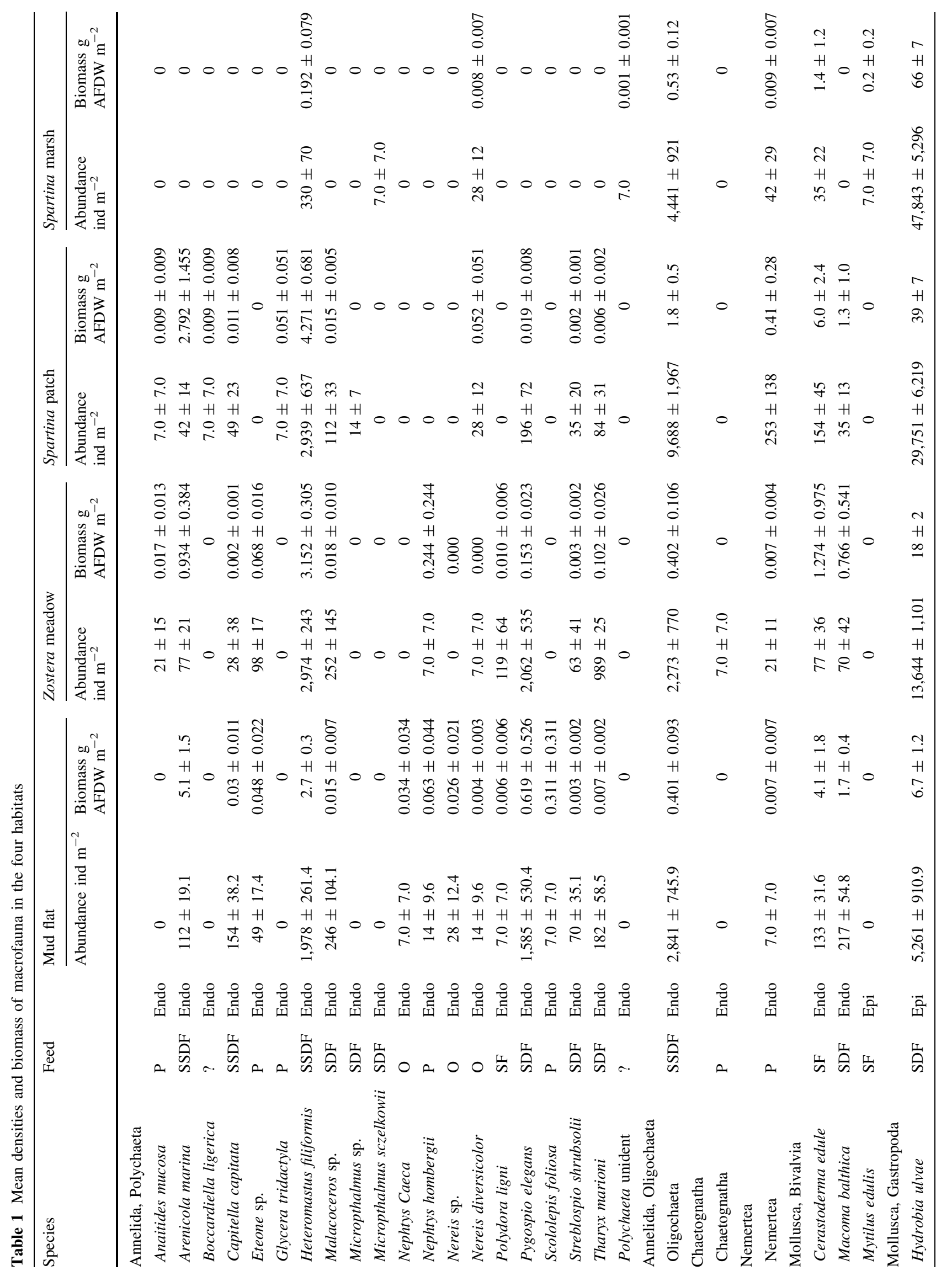




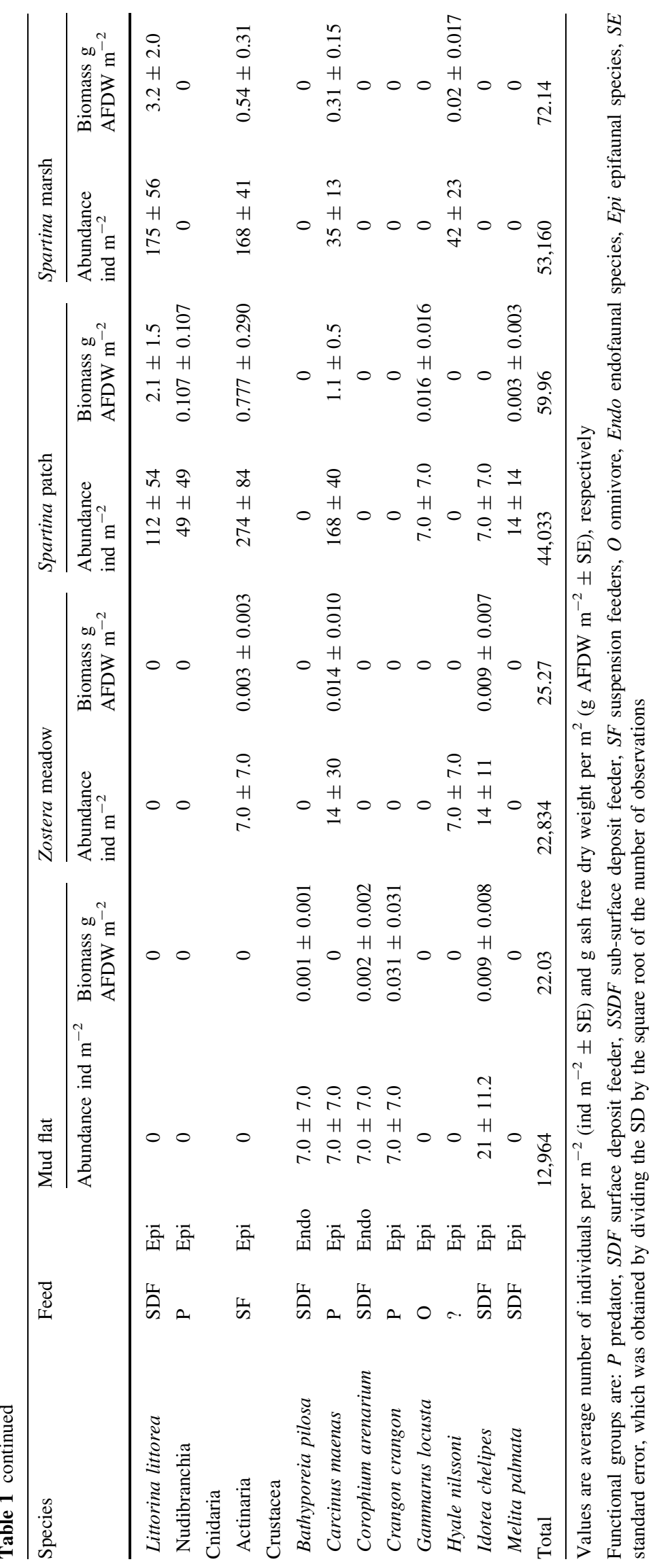


detritus within the sediment (e.g., Oligochaeta, Heteromastus filiformis); (4) predators (P) that prey on other benthos species (e.g., Nepthys cirrosa, Carcinus maenas); (5) omnivores (O) that have several feeding strategies (e.g., Nereis diversicolor).

Sediment grain size, chl. $a$ and organic matter analysis

Sediment samples were analyzed for grain size distribution (median grain size and the mud content being the percentage of silt and clay, i.e., $\%<63 \mu \mathrm{m}$ ) by laser diffraction technique performed with a Malvern Mastersizer 2000. Particulate organic carbon and nitrogen content of the sediments were analyzed by a Carlo Erba elemental analyzer, type NA-1500. The phosphor content of the sediments was determined by using Perkin Elmer ICP-OES, type Optima 3300DV.

For chlorophyll analysis the freeze dried sediment samples were first homogenized with a mortar. Then approximately $1 \mathrm{~g}$ of the sediment was placed with $10 \mathrm{ml}$ $90 \%$ acetone in a little pulverize bottle. After the sediment was pulverized, the extract was frozen with liquid $\mathrm{CO}_{2}$. The extract was then placed in a centrifuge for $3 \mathrm{~min}$ at $1,500 \mathrm{rpm}$. The supernatant was finally placed in the Waters Fluorescentie detector 474 for pigments analysis.

\section{Statistical analysis}

Several diversity indices were calculated using PRIMER 5.0 (Clarke 1993), in order to compare benthic assemblages at the different habitats. First, we calculated Margalef's index $(d)$ for species richness, which gives the number of species present for a given number of individuals:

$d=(S-1) / \log N$

where $S$ is the total number of species and $N$ the total number of individuals. Second, species diversity was calculated using Shannon's-Wiener diversity index $\left(H^{\prime}\right)$ :

$H^{\prime}=-\sum_{i} p_{i} \times \log _{\mathrm{e}}\left(p_{i}\right)$

where $p_{i}$ is the proportion of the total count arising from the $i$ th species. Third, we used Pielou's evenness index $\left(J^{\prime}\right)$ to expresses how evenly the individuals are distributed among the different species:

$J^{\prime}=H^{\prime} / H_{\max }^{\prime}$

where $H_{\max }^{\prime}$ is the maximum possible value of ShannonWiener diversity for a given number of individuals and species.

One-way ANOVA with a posteriori Tukey's HSD tests were used to examine between-habitat differences in environmental and faunal properties $(p<0.05)$. Data were tested for normality and heteroscedasticity and, when necessary, square root or log-transformed.

Similarities and differences in macrofaunal assemblages were explored using non-metric multidimensional scaling (n-MDS), based on Bray-Curtis similarity indices on logtransformed, unstandardized data. Stress values indicate how well the solution (two-dimensional MDS plot) reflects the similarities among cores. Values $<0.1$ are good and $<0.2$ are useful (Clarke 1993). Overall and pair-wise comparisons for significant differences in macrofaunal composition between habitats were made using analysis of similarity (ANOSIM) (Clarke 1993). Similarity percentage (SIMPER) analyses were used to determine the percent of similarity of samples and the particular taxa responsible for differences between groups (Clarke 1993). These multivariate analyses (MDS) and the diversity measures were performed with the program Primer 5.0 (Clarke 1993).

\section{Results}

Benthic macrofaunal assemblage structure in the four habitats

Multivariate analyses of the benthic macrofaunal assemblages revealed that the macrobenthos distribution over the four habitats (mudflat, Z. noltii, Spartina patch, Spartina marsh) was best separated by species abundance (Fig. 2). Differences were less clear when either taxonomic groups or feeding modes (details in Table 1) were used. Figure 2 shows that the four different habitats are characterized by different assemblages (ANOSIM, $p=0.001, R=0.73$, in line with hypothesis 2 ). The mudflat assemblage and $Z$. noltii meadow assemblage showed highest similarities (SIMPER, $69 \%$ similarity, ANOSIM, $p<0.001, R=0.33$ ), whereas the Spartina marsh assemblage showed the highest

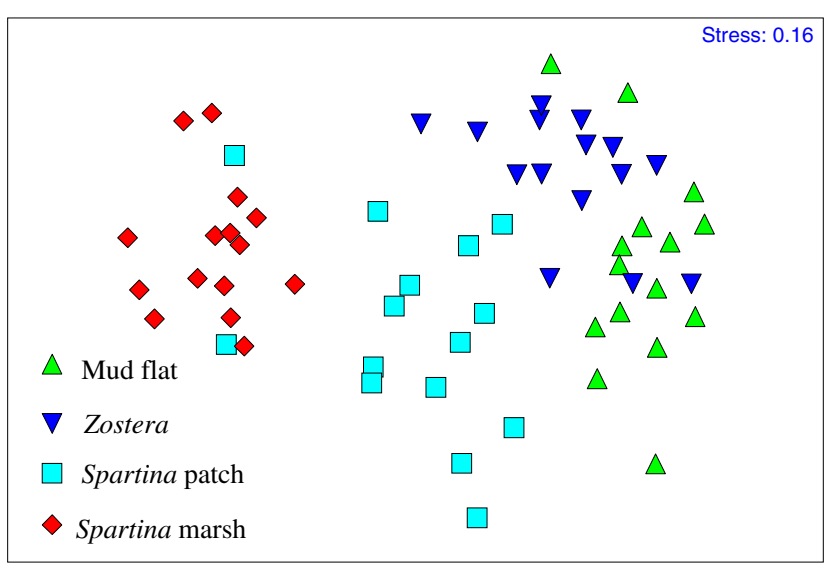

Fig. 2 MDS ordination of species abundance data from the four different areas 
dissimilarity with these two areas [SIMPER, $47 \%$ (mudflat) and $44 \%$ (Z. noltii) similarity, ANOSIM, both $p<0.001$, $R=0.99]$. The Spartina patch assemblage has an intermediate position in the ordination diagram, showing a similarity of $61 \%$ with the other habitats (ANOSIM, $p<0.001, R=0.66$ ). Below we analyze to which extend these differences in macrobenthic assemblages can be explained by differences in the engineered habitat available to benthos and follow our hypotheses.

Characterization of the (engineered) habitat available to benthos

Both shoot and root biomasses were significantly higher in $S$. anglica than in $Z$. noltii, with highest values in the Spartina marsh (Table 2). Shoot density was, however, significantly higher in the $Z$. noltii vegetation. At low tide $Z$. noltii shoots typically lie down on the sediment surface (shoot length on average $15 \mathrm{~cm}$ ), whereas the stiff Spartina stems are typically $30 \mathrm{~cm}$ in height. These morphological differences between Spartina and Z. noltii, cause the different engineering characteristics of both plant species with respect to habitat complexity, reducing hydrodynamic energy, trapping of particulate material and increasing bottom elevation.

Measurements of elevation (meters above NAP, which is similar to mean sea level) revealed that mud flat $(1.52 \pm 0.01 \mathrm{~m} \mathrm{NAP})$ and $Z$. noltii $(1.59 \pm 0.02 \mathrm{~m} \mathrm{NAP})$ areas had roughly the same elevation whereas the Spartina vegetation had a slightly, but significantly higher elevation (Spartina patch $1.75 \pm 0.03 \mathrm{~m}$ NAP, Spartina marsh $1.69 \pm 0.03 \mathrm{~m}$ NAP; Table 2). The spatial heterogeneity in elevation is, however, too small to account for major differences in macrobenthic communities. The maximum difference in immersion time between sampling sites was $<10 \%$ per tidal cycle.

The sediment analysis clearly showed retention of small particles within vegetation (Table 2). Median grain size was significantly higher at mud flat $(179 \pm 1.8 \mu \mathrm{m})$ compared to the vegetated areas $(119-138 \mu \mathrm{m})$. Mud content (i.e., fraction $<63 \mu \mathrm{m}$ ) was significantly higher in vegetated areas $(Z$. noltii $27 \pm 2.3 \%$; Spartina patch $18 \pm 2.3 \%$; Spartina marsh $24 \pm 3.6 \%$ ) than at the unvegetated mudflat $(6.8 \pm 0.64 \%)$, but no significant differences were observed within the different vegetations (Fig. 3). The particulate organic carbon and organic nitrogen content were highest at the Spartina marsh, whereas all other sites had much lower content of a similar magnitude (Fig. 3). A similar pattern was observed for chl. $a$ (Fig. 3). Overall it is clear that vegetations have a significant effect on sediment properties, and that differences within the three vegetated habitats were in general small, except for the Spartina marsh showing a higher organic material content.

Macrofaunal diversity, abundance and biomass

A total of 38 macrobenthic invertebrate taxa were identified in this study, belonging to six different phyla; $82 \%$ were endofaunal species and 18\% epifaunal species (Table 1). The mudflat, Zostera meadow and Spartina patch showed a similar total number of species $(24,22$ and 24 species, respectively) and a similar number of endofaunal species (20,17 and 16), whereas these numbers were much lower in the Spartina marsh (13 total, 7 endofaunal; Table 3). The number of epifaunal species was highest in the Spartina patch vegetation (8) and lowest at the mud flat (4; Table 3).

Species richness $(d)$ was similar for the mud flat $(10.2 \pm 0.40), Z$. noltii meadow $(9.07 \pm 0.55)$ and Spartina patch $(9.73 \pm 0.55)$, but significantly dropped in the Spartina marsh area $(5.73 \pm 0.55$; Table 3$)$. Endofaunal species richness was highest at the mud flat and was lower in the vegetated areas, especially in the Spartina marsh. Epifaunal species richness showed the opposite pattern, with significantly higher values in the Spartina patch and

Table 2 Habitat and vegetation characteristics of the four habitats (average \pm SE): elevation $(\mathrm{m})$, shoot dry weight ( $\mathrm{g} \mathrm{AFDW} \mathrm{m}^{-2}$ ), number of stems (number $\mathrm{m}^{-2}$ ), roots dry weight $\left(\mathrm{g} \mathrm{AFDW} \mathrm{m}^{-2}\right)$, mud content $(\%<63 \mu \mathrm{m})$, median grain size $(\mu \mathrm{m})$, Arenicola sand piles $\left(\right.$ number $\left.\mathrm{m}^{-2}\right)$ and algae dry weight $\left(\mathrm{g}\right.$ AFDW $\mathrm{m}^{-2}$ )

\begin{tabular}{|c|c|c|c|c|}
\hline & Mud flat & Zostera meadow & Spartina patch & Spartina marsh \\
\hline Number of stems (number $\mathrm{m}^{-2}$ ) & 0 & $19,683 \pm 1,274^{\mathrm{a}}$ & $335 \pm 68.3^{\mathrm{b}}$ & $454 \pm 28.9^{\mathrm{b}}$ \\
\hline Shoot biomass (g AFDW $\mathrm{m}^{-2}$ ) & 0 & $48 \pm 3.5^{\mathrm{a}}$ & $136 \pm 27.5^{\mathrm{b}}$ & $338 \pm 30.3^{c}$ \\
\hline Root biomass (g AFDW m ${ }^{-2}$ ) & 0 & $185 \pm 24.09^{\mathrm{a}}$ & $900 \pm 74.9^{\mathrm{b}}$ & $1,471 \pm 126^{\mathrm{c}}$ \\
\hline Elevation (m NAP) & $1.5 \pm 0.01^{\mathrm{a}}$ & $1.6 \pm 0.02^{\mathrm{a}}$ & $1.8 \pm 0.03^{\mathrm{b}}$ & $1.7 \pm 0.03^{\mathrm{b}}$ \\
\hline Mud content $(\%)$ & $6.8 \pm 0.64^{\mathrm{a}}$ & $27 \pm 2.3^{\mathrm{b}}$ & $18 \pm 2.3^{\mathrm{b}}$ & $24 \pm 3.6^{\mathrm{b}}$ \\
\hline Median grain size $(\mu \mathrm{m})$ & $179 \pm 1.8^{\mathrm{a}}$ & $119 \pm 6.1^{\mathrm{b}}$ & $138 \pm 7.6^{\mathrm{b}}$ & $138 \pm 14.1^{\mathrm{b}}$ \\
\hline Arenicola sand piles (number $\mathrm{m}^{-2}$ ) & $63 \pm 2.8^{\mathrm{a}}$ & $30 \pm 5.1^{\mathrm{b}}$ & $14 \pm 3.0^{\mathrm{c}}$ & $0^{\mathrm{d}}$ \\
\hline
\end{tabular}

Elevations are given in meters above the Dutch ordnance level (NAP), which is similar to mean sea level. Letters indicate significant differences among habits using a posteriori Tukey HSD tests 
Fig. 3 Average $( \pm S E)$ mud content, organic matter content (\% organic $\mathrm{C})$, nitrogen (\% N-Tot.) and chl. $a$ content in the four habitats
Table 3 Mean $( \pm$ SE) values for the diversity measures (total number of species, species richness, Shannon-Wiener $H^{\prime}$ diversity, evenness $J^{\prime}$ ), mean abundance (ind $\mathrm{m}^{-2}$ ) and mean biomass (g AFDW m ${ }^{-2}$ ) observed at each sample site
Endo endofauna, epi epifauna

Letters indicate significant differences among habits using a posteriori Tukey HSD tests
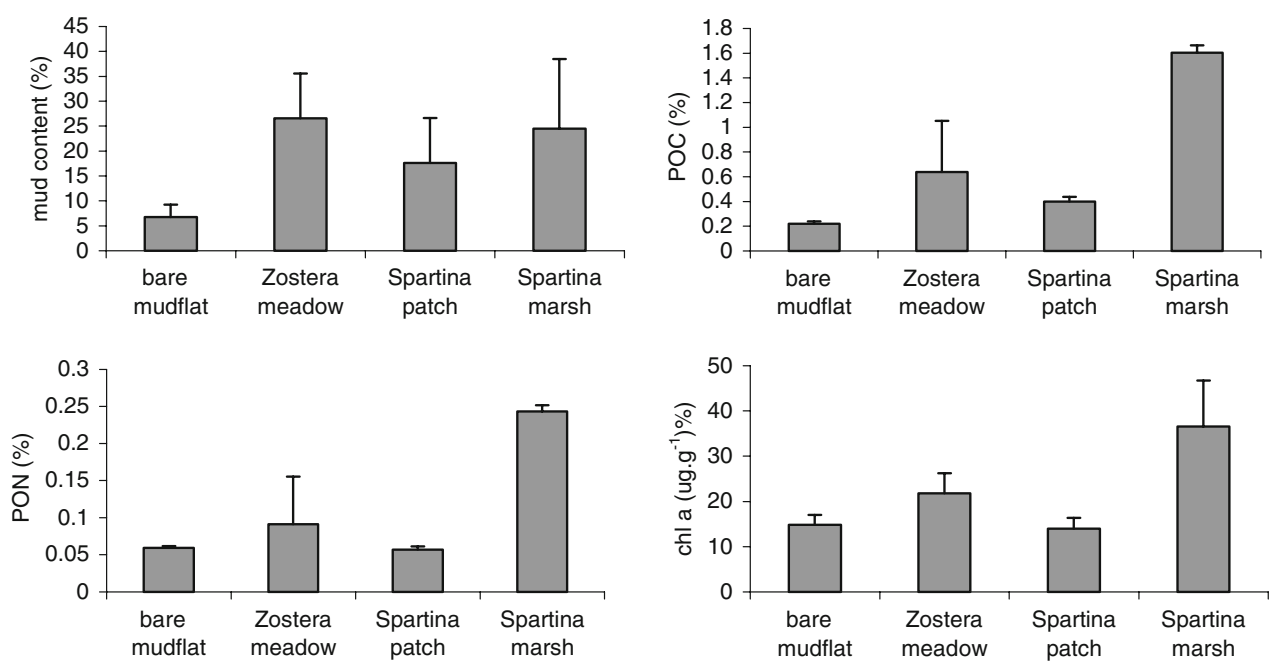

\begin{tabular}{|c|c|c|c|c|}
\hline & Mud flat & Zostera meadow & Spartina patch & Spartina marsh \\
\hline \multicolumn{5}{|c|}{ Total number of species } \\
\hline Endo & 20 & 17 & 16 & 7 \\
\hline Epi & 4 & 5 & 8 & 6 \\
\hline Total & 24 & 22 & 24 & 13 \\
\hline \multicolumn{5}{|c|}{ Species richness $(d)$} \\
\hline Endo & $8.67 \pm 0.39^{\mathrm{a}}$ & $7.67 \pm 0.56^{\mathrm{ab}}$ & $6.80 \pm 0.48^{b}$ & $2.67 \pm 0.19^{c}$ \\
\hline Epi & $1.4 \pm 0.13^{\mathrm{a}}$ & $1.4 \pm 0.13^{\mathrm{a}}$ & $2.93 \pm 0.32^{\mathrm{b}}$ & $3.07 \pm 0.23^{\mathrm{b}}$ \\
\hline Total & $10.2 \pm 0.40^{\mathrm{a}}$ & $9.07 \pm 0.55^{\mathrm{a}}$ & $9.73 \pm 0.55^{\mathrm{a}}$ & $5.73 \pm 0.55^{\mathrm{b}}$ \\
\hline \multicolumn{5}{|c|}{ Shannon-Wiener $\left(H^{\prime}\right)$} \\
\hline Endo & $1.42 \pm 0.07^{\mathrm{a}}$ & $1.38 \pm 0.07^{\mathrm{a}}$ & $0.81 \pm 0.08^{\mathrm{b}}$ & $0.44 \pm 0.08^{\mathrm{c}}$ \\
\hline Epi & $0.05 \pm 0.02^{\mathrm{ab}}$ & $0.02 \pm 0.01^{\mathrm{a}}$ & $0.19 \pm 0.07^{\mathrm{b}}$ & $0.06 \pm 0.01^{\mathrm{ab}}$ \\
\hline Total & $1.50 \pm 0.04^{\mathrm{a}}$ & $1.24 \pm 0.08^{\mathrm{a}}$ & $0.93 \pm 0.09^{b}$ & $0.39 \pm 0.04^{\mathrm{c}}$ \\
\hline \multicolumn{5}{|c|}{ Evenness $\left(J^{\prime}\right)$} \\
\hline Endo & $0.66 \pm 0.03^{\mathrm{a}}$ & $0.70 \pm 0.02^{\mathrm{a}}$ & $0.43 \pm 0.04^{\mathrm{b}}$ & $0.45 \pm 0.08^{\mathrm{b}}$ \\
\hline Epi & $0.18 \pm 0.05^{\mathrm{a}}$ & $0.09 \pm 0.01^{\mathrm{a}}$ & $0.16 \pm 0.04^{\mathrm{a}}$ & $0.06 \pm 0.01^{\mathrm{a}}$ \\
\hline Total & $0.65 \pm 0.02^{\mathrm{a}}$ & $0.57 \pm 0.03^{\mathrm{a}}$ & $0.41 \pm 0.03^{\mathrm{b}}$ & $0.22 \pm 0.03^{c}$ \\
\hline \multicolumn{5}{|c|}{ Abundance (ind $\mathrm{m}^{-2}$ ) } \\
\hline Endo & $7,646 \pm 1,137^{\mathrm{a}}$ & $9,148 \pm 976^{\mathrm{ab}}$ & $13,651 \pm 1,936^{\mathrm{b}}$ & $4,890 \pm 903^{\mathrm{a}}$ \\
\hline Epi & $5,303 \pm 914^{\mathrm{a}}$ & $13,686 \pm 1,741^{\mathrm{a}}$ & $30,382 \pm 6,144^{\mathrm{b}}$ & $48,271 \pm 5,330^{b}$ \\
\hline Total & $12,964 \pm 1,910^{\mathrm{a}}$ & $22,834 \pm 1,957^{\mathrm{a}}$ & $44,034 \pm 5,878^{\mathrm{b}}$ & $53,160 \pm 5,643^{b}$ \\
\hline \multicolumn{5}{|c|}{ Biomass (g AFDW m ${ }^{-2}$ ) } \\
\hline Endo & $15 \pm 2.3^{\mathrm{ab}}$ & $7.15 \pm 1.41^{\mathrm{ac}}$ & $17 \pm 2.9^{\mathrm{ab}}$ & $2.09 \pm 1.18^{\mathrm{c}}$ \\
\hline Epi & $6.77 \pm 1.17^{\mathrm{a}}$ & $18 \pm 2.2^{\mathrm{b}}$ & $43 \pm 6.6^{c}$ & $70 \pm 8.8^{\mathrm{d}}$ \\
\hline Total & $22.03 \pm 2.71^{\mathrm{a}}$ & $25.27 \pm 2.56^{\mathrm{a}}$ & $59.96 \pm 6.87^{\mathrm{b}}$ & $72.14 \pm 8.67^{\mathrm{b}}$ \\
\hline
\end{tabular}

Spartina marsh as compared to the Zostera meadow and the bare mud flat (Table 3). Total and endofaunal diversity $\left(H^{\prime}\right)$ and evenness $\left(J^{\prime}\right)$ was similar at the mud flat and Zostera meadow, but significantly lower in the Spartina patch and Spartina marsh. Epifaunal diversity and evenness showed low values without a clear pattern (Table 3 ).
Total mean abundance (individuals $\mathrm{m}^{-2}$ ) and biomass $\left(\mathrm{g} \mathrm{AFDW} \mathrm{m}^{-2}\right.$ ) followed the sequence bare mudflat $<$ Zostera meadow $<$ Spartina patch $<$ Spartina marsh (Table 3). This increase was mainly due to the increase in epifaunal abundance and biomass in the vegetated areas. It is noted that the increase in epifaunal 
abundance was mainly due to a huge increase of a single species: the gastropod $H$. ulvae (Table 1). Endofaunal abundance showed a different pattern, with the highest abundances in the Spartina patch, followed by the Zostera meadow, the mud flat and the lowest abundance in the Spartina marsh. This pattern was not reflected in the biomass, indicating that individuals in the Spartina patch vegetation were on average much smaller than on the mudflat. Endofaunal abundance and biomass were lowest in the Spartina marsh (Table 3).

Macrofaunal functional groups as defined by feeding modes

As the interaction of ecosystem engineering vegetations with hydrodynamic conditions may affect supply of food to specific macrobenthic feeding modes, we classified all animals in five functional groups. Table 4 summarizes the results for the macro-benthic species that contribute quantitatively most to each feeding mode. This table suggests that the division in endo- and epibenthos is more important for explaining the distribution of animals over habitats, than feeding types. The Spartina data reveal that patch size is also highly important.

The abundance (Fig. 4) and biomass (Fig. 5) of SDFs that typically feed on diatoms on the surface of the sediment were dominated by the epibenthic gastropod grazer H. ulvae. It is clearly seen that both the abundance and the biomass increases in the following order: bare mudflat $<$ Zostera meadow $<$ Spartina patch $<$ Spartina marsh. Compared to this effect, changes in endobenthic SDFs are small (Fig. 4, 5), but showing the opposite trend as for the epibenthic SDF. That is, endobenthic SDF are nearly absent in the Spartina habitats, and show highest densities in the Zostera meadows and the bare mudflat.

The abundance of SSDF that predominantly feed on micro-organisms, phytobenthos and detritus was highest in the small Spartina patches, and equal in all other habitats (Fig. 4), although contributing species clearly differ between habitats (Table 1). Combining the biomass data (Fig. 5) with the abundance data (Fig. 4), indicates that only small animals can live in the Spartina marsh and small Spartina patches.

Suspension feeders were not very abundant at the study site, due to the high tidal level of the sampling stations. They appeared to be most abundant in the small Spartina patches, where epi- and endobenthic SFs could co-exist (Fig. 4). In the Zostera meadow and at the mudflat, the abundance of epibenthic SFs was negligible. In the Spartina marsh, the abundance of the endobenthic SFs diminished, whereas there was still an epibenthic assemblage of SFs present (Fig. 4). The biomass of the

Table 4 Overview indicating for the most important macro-benthic species, how the species abundance in three vegetated sites (Zostera meadow, Spartina patch and Spartina marsh) compare to that at the mud flat

\begin{tabular}{|c|c|c|c|c|c|}
\hline Functional groups & Species & & $\begin{array}{l}\text { Mud flat } \rightarrow \text { Zostera } \\
\text { meadow }\end{array}$ & $\begin{array}{l}\text { Mud flat } \rightarrow \text { Spartina } \\
\text { patch }\end{array}$ & $\begin{array}{l}\text { Mud flat } \rightarrow \text { Spartina } \\
\text { marsh }\end{array}$ \\
\hline \multirow[t]{4}{*}{ Sub-surface deposit feeders } & Arenicola marina & Endo & $(-)$ & - & $x$ \\
\hline & Capitella capitata & Endo & -- & $(-)$ & $x$ \\
\hline & Heteromastus filiformis & Endo & $(+)$ & $(+)$ & --- \\
\hline & OLIGOCHAETA & Endo & $(-)$ & ++ & $(+)$ \\
\hline \multirow[t]{7}{*}{ Surface deposit feeders } & Malacoceros & Endo & $(+)$ & $(-)$ & $x$ \\
\hline & Tharyx marioni & Endo & $(+)$ & $(-)$ & $x$ \\
\hline & Macoma balthica & Endo & --- & -- & $x$ \\
\hline & Pygospio elegans & Endo & $(+)$ & --- & $x$ \\
\hline & Streblospio shrubsolii & Endo & $(-)$ & $(-)$ & $x$ \\
\hline & Hydrobia ulvae & Epi & +++ & +++ & +++ \\
\hline & Littorina littorea & Epi & $\times$ & + & +++ \\
\hline \multirow[t]{3}{*}{ Suspension feeders } & Polydora ligni & Endo & ++ & $\times$ & $\times$ \\
\hline & Cerastoderma edule & Endo & $(-)$ & $(+)$ & - \\
\hline & Actinaria & Epi & $(+)$ & +++ & +++ \\
\hline Omnivores & Nereis diversicolor & Endo & $(-)$ & $(+)$ & $(+)$ \\
\hline \multirow[t]{2}{*}{ Predators } & Carcinus maenas & Epi & $(+)$ & ++ & $(+)$ \\
\hline & Nemertea & Endo & $(+)$ & ++ & $(+)$ \\
\hline
\end{tabular}

The symbols used in the table have the following meaning: $(+)$ or $(-)$ indicates an increasing or decreasing trend, but no significant differences $(p>0.05$, One-way ANOVA); + or - indicates an increase or decrease with $p<0.05 ;++$ or -- the same for $0.05<p>0.01 ;+++$ or --- the same for $p<0.001 ; \times$ indicates that the abundance was reduced to 0 

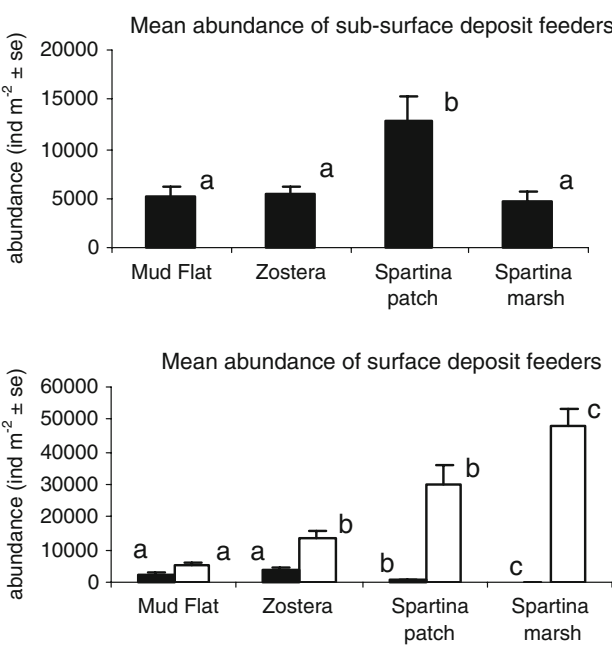

Fig. 4 Mean abundance (ind $\mathrm{m}^{-2} \pm \mathrm{SE}$ ) observed for each feeding mode at the four different habitats. Closed bars represent endofauna, open bars epifauna. Endofaunal and epifaunal averages were

epibenthic SFs was in all cases low compared to that of the endobenthic SFs (Fig. 5).

The predators $(\mathrm{P})$ that prey upon other benthos species showed a comparable pattern as that of the SFs, in that they were most abundant in the small Spartina patches, where both epi- and endobenthic predators could co-exist (Fig. 4). The epibenthic predator Carcinus maenas was most abundant (Fig. 4) and had highest biomass (Fig. 5) in the small Spartina patches. In all other habitats their abundance was negligible, but they did have a significant biomass in the Spartina marsh. The endobenthic predators (Nemertea) appeared to be most abundant at the Spartina patches, and least abundant at the Spartina marsh, although not significant.
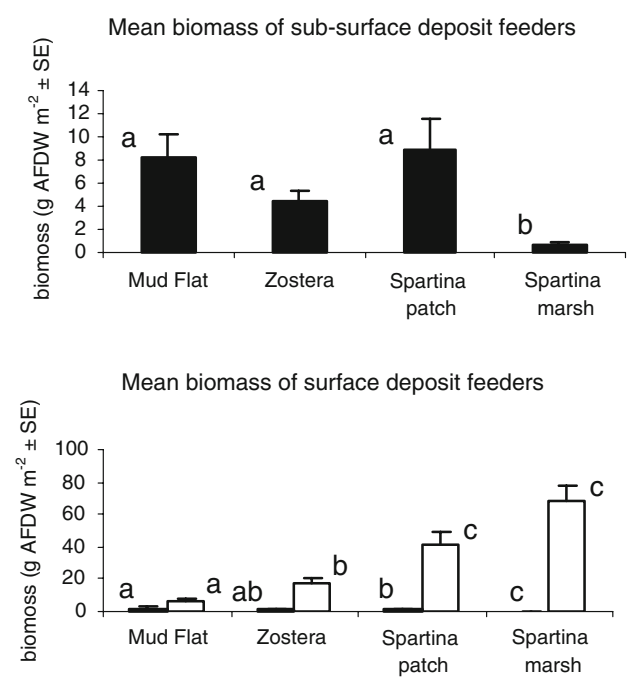

Fig. 5 Mean biomass (g AFDW $\mathrm{m}^{-2} \pm \mathrm{SE}$ ) observed for each feeding group at the four different areas. Closed bars endofauna, open bars epifauna. Endofaunal and epifaunal biomasses were
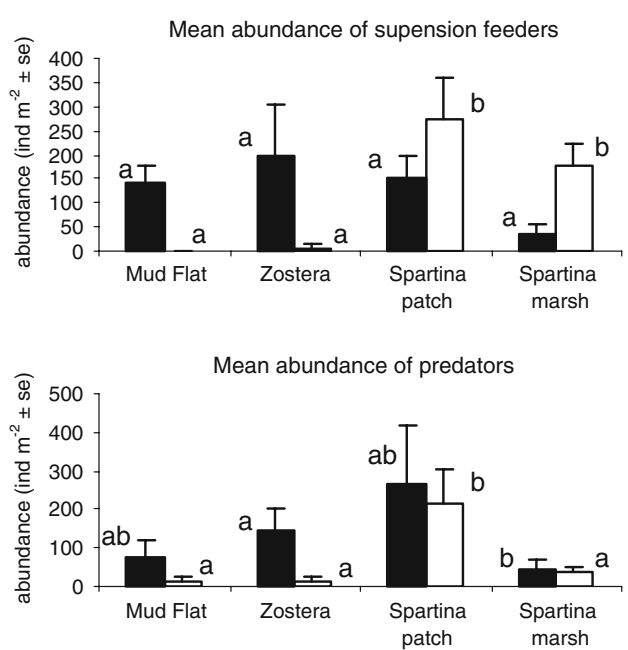

analyzed separately for significant differences between the four habitats. Letters indicate significant differences among habits using a posteriori Tukey HSD tests

\section{Discussion}

Several studies demonstrated opposite effects of ecosystem engineers on species richness and abundances (Jones et al. 1997; Crooks 2002; Wright and Jones 2004), complicating the identification of underlying mechanisms. We test a number of hypothesis related to the importance of habitat complexity, productivity and scale for effects of ecosystem engineers on biodiversity, using intertidal flats as a model system. We observed that macrobenthic assemblages significantly differ when comparing two co-occurring vegetations with contrasting ecosystem engineering strength (Z. noltii and S. anglica; cf. Bouma et al. 2005) and the nearby non-engineered mudflat. The sometimes
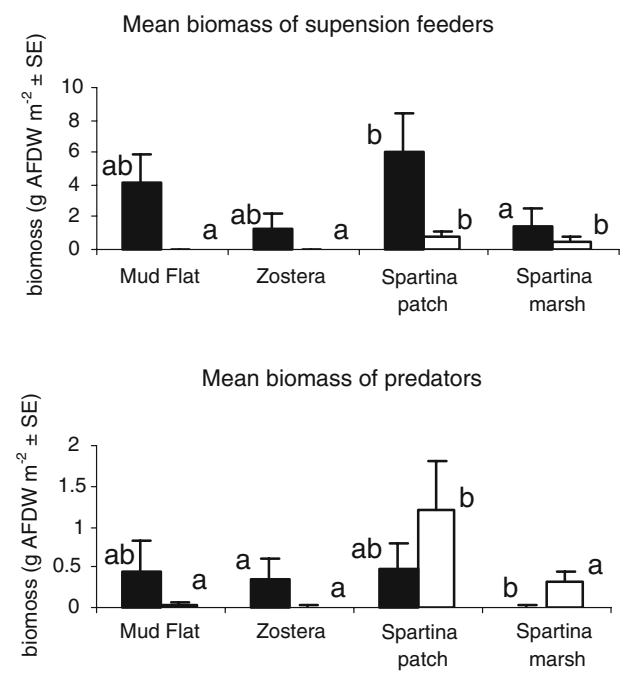

analyzed separately for significant differences between the four habitats. Letters indicate significant differences among habits using a posteriori Tukey HSD tests 
relatively high values for similarity between the four different habitats, reflect that many differences are mainly expressed as major shifts in dominance of co-occurring species, rather than a complete shift in species composition. Our results most strongly supported hypothesis 3, stating that the increased above-ground habitat complexity in the presence of vegetations support a shift from endotowards epibenthic species. This shift appears to be much more important than changes in feeding type, refuting our hypothesis 2 . In line with hypothesis 4 , we found a more diverse benthic macrofaunal assemblage in small Spartina patches than in larger Spartina meadows. In line with hypothesis 1 , we also observed more fine-grained sediment in the vegetated habitats, relative to the unvegetated tidal flat. Spartina habitats were also more elevated compared to the unvegetated mudflat and the Zostera meadow. This agrees well with several studies describing increased sediment deposition rates and reduced particles sizes in vegetated habitats relative to unvegetated tidal flats, due to the attenuation of tidal and wave energy by the plants (e.g., see Fonseca and Cahalan 1992; Yang 1998; Leonard et al. 2002; Neira et al. 2006). Abiotic differences within the three vegetated habitats remained, however, small: sediment grain size was similar; only POC and chl. $a$ showed an increased concentration in the Spartina marsh. These observations suggest that sediment properties and soil chemistry, which have been shown to be a major factor in other areas (e.g., Neira et al. 2006), are not primarily driving the faunal differences in our system. Overall, our results suggest that increased above-ground habitat complexity by vegetations supports a shift from endo- towards epibenthic species (cf. hypothesis 3), and that this effect is affected by patch size (cf. hypothesis 4 ) and not as much by a change in sediment properties (refuting hypothesis 1 ) or feeding type (refuting hypothesis 2).

The epibenthos in the vegetated areas was strongly dominated by the small diatom-grazing snail $H$. ulvae, which was especially clear for Spartina, and in accordance with previous observations (for seagrasses, see Bostrom and Bonsdorff 1997; Bachelet et al. 2000; Blanchet et al. 2004; Cottet et al. 2007; for salt marsh plants see Kneib 1984; Mc Corry and Otte 2000; Whaley and Minello 2002; Cottet et al. 2007). It is not clear to which extend this increase is due to enhanced food availability (cf. suggestion Blanchet et al. 2004) rather than ecosystem engineering. According to previous studies, this opportunistic small gastropod may respond to the high organic matter content (Bostrom and Bonsdorff 1997) and the food present on the macrophytes blades (cf. found for Bittium reticulatum; Curras et al. 1993). However, we expect this shift for an important part to be caused by a combined effect of protection against predation and sheltering from hydrodynamic forces by the enhanced habitat complexity. Unfortunately, the descriptive nature of our study does not provide in depth insight in the underlying processes.

Overall, our results agree with the general finding that engineering species that increase habitat complexity also tend to increase the diversity and/or the abundance of organisms (Crooks 2002). Our results show a clear increase in abundance in the vegetated areas, but this is because one or a few species became very abundant (increased dominance), rather than by an increased species diversity. The effect of structural complexity of macrophyte vegetations like seagrasses and salt marsh species, have been well described with respect to protection from predation, reduction of current velocity, retention of particle and the accretion of sediment. Several studies show that these physical changes tend to increase macrofaunal species richness and/or abundances (seagrasses: Orth 1992; Heck et al. 1995; Bartholomew, 2002; salt marsh plant: Rader 1984; Netto et al. 1997, Netto and Lana 1999; Whaley and Minello 2002; Brusati and Grosholz 2006), but with exceptions, especially for the salt marsh species (e.g., Moseman et al. 2004; Neira et al. 2005; Levin and Talley 2000). The contrasting influence of Spartina species on macrobenthos composition may be due to conditional outcomes of ecosystem engineering. For other systems, it has been demonstrated that depending on the physical forcing, effects of ecosystem engineers on biodiversity may be quite different (Norkko et al. 2006). Another explanation for variable outcomes of increased structural complexity might be that in some systems, predators themselves may also benefit from protection against predation, thereby increasing predation rates on other smallest infaunal species (Bowden et al. 2001). According to Cottet et al. (2007), other stresses may limit the structuring effect of increased habitat complexity on infaunal assemblages. In case of Zostera, Spartina and bare mudflat located at high elevations, desiccation may become the dominant stress factor determining infauna community structure. This would partly fit present results, but does not explain the observation that the increased above-ground habitat complexity in the presence of vegetations support a shift from endo- towards epibenthic species (cf. hypothesis 3 ). Effects of the habitat complexity on recruitment of larvae and the re-suspension of adults (Neira et al. 2006) as well as other factors such as food availability might also play a role.

It is well recognized that ecosystem engineering effects on macrofaunal distributions are hard to separate in effects via food availability versus effects via physical habitat modification, including habitat complexity (Heck and Orth 1980; Irlandi and Peterson 1991; Jones et al. 1994). For example, whereas it was originally thought that the distributions of three species of the fiddler crab $U c a$, were due to food availability, Ringold (1979) demonstrated that this 
was due to the root mat density of Spartina. Amphipod population growth has been shown to be a complex mixture of refuge against predation and food between seagrasses and macroalgae habitats (Corona et al. 2000). However, in vegetated areas, blue crab growth has been demonstrated to be predominantly controlled by food availability rather than protection from predation (Seitz et al. 2005). Shading effects of the vegetation can play an important role in determining the main food source to benthic assemblages (Whitcraft and Levin 2007). Levin et al. (2006) observed a trophic shift in sediments invaded by Spartina compared to uninvaded sediments, with a shift from an algae-based to a detritus-based food web. If we consider only the endobenthic part, SSDFs (Heteromastus, oligochaetes) become indeed relatively more important in the Spartina habitats as compared to the Zostera meadow and the bare mudflat. However, when including the epibenthic part, a different picture emerges, with an increased importance of SDFs and grazers. This again stresses the importance of including epibenthic fauna when studying salt marsh ecosystem engineers. In line with previous studies that underline the difficulty in assessing most important factors in explaining macrobenthic distributions in- and outside engineered areas, we also cannot provide general statements on the relative importance of food availability versus physical habitat modification. In our particular case, food availability seems to be of lesser importance than habitat modification and habitat complexity. More important, the present study suggests how comparison of ecosystem engineers with contrasting extend on habitat modification, adds strength to the analysis.

A complicating factor when comparing Z. noltii and $S$. anglica, is that in addition to above-ground differences, species also differ below-ground. The much higher root mass and sediment compaction in Spartina sites may physically hamper establishment and survival of endobenthic species (e.g., Brusati and Grosholz 2006). For example, sediment compaction and fine grain size distribution hampers settlement of A. marina in Spartina patches (van Wesenbeeck et al. 2007). Although we observed Arenicola in both the Zostera meadow and the small Spartina patches, this species was completely absent in the Spartina marsh. Earlier studies also suggested that polychaetes abundance is negatively influenced by the presence of vegetation since the root/rhizome system of macrophytes hamper these worms to penetrate into the sediment and sustain burrows or tubes (Stoner 1980; Orth et al. 1984; Webster et al. 1998; Hily and Bouteille 1999; Brusati and Grosholz 2006). Since the root/rhizome system in Zostera is less dense than that of Spartina and sediment is less compacted in Zostera meadows, small endobentic species may be able to penetrate the sediment in the presence of seagrasses (Brenchley 1982, this study). The only two annelid species that were abundantly present in the Spartina vegetation were the polychaete Heteromastus filiformis and oligochaetes. Both are small, sub-surface deposit feeding species, often reported in other studies to be common in Spartina vegetations (e.g., Neira et al. 2005, 2007). Particularly oligochaetes can reach high abundances in salt marshes, as they can live in the microhabitat created by the root system of the plants and are capable to feed upon Spartina detritus (Levin et al. 2006).

The root/rhizome of both Z. noltii and S. anglica seemed to affect bivalve's abundances. The clam $M$. balthica was more harmed where vegetation was present probably because it burrows deeper than the cockle Cerastoderma and the vegetation's root/rhizome system preclude $M$. balthica to penetrate into the sediment. Cockles observed at Spartina marsh were bigger than the cockles from the unvegetated area (i.e., 0.4 vs. $0.3 \mathrm{~g}$, respectively, cf. Table 1) suggesting that cockles able to settle in the vegetation can reach bigger sizes likely due to a reduction of predation by birds similar to shown for comparable systems (Irlandi and Peterson 1991; Irlandi 1994). Cockles in the Spartina habitats typically were living almost on top of the sediment, whereas on the mudflat cockles lived typically a few $\mathrm{cm}$ burrowed into the sediment.

In addition to the generalized idea that macrophytes structural density enhances macrofaunal densities (Heck and Orth 1980), a patchy distribution and the presence of edges have been found to support higher faunal densities than continuous or dense patches. For example, patchy/ fragmented seagrass systems were found to support higher densities of blue crab juveniles (Hovel and Lipicius 2001), macrofauna (Bowden et al. 2001) and epifauna (Healey and Hovel 2004), although other factors like predation and foraging rates can be higher in patchy areas (Irlandi and Peterson 1991; Irlandi 1994, 1996; Irlandi et al. 1995). Present results underlined the importance of patchiness in structuring macrofaunal assemblages as well, as we found significantly higher species richness at the Spartina patch than Spartina marsh. A more diverse assemblage was observed in the Spartina patch, as both endo- and epibenthic species were present. The Spartina patch area allowed more species to be present and enhanced the abundances of some of them. Together with patchiness, also the time the ecosystem engineer being present may be important. Assuming that smaller Spartina patches have been established more recently, the sediment of the Spartina patches have a significantly lower below-ground biomass, indicating a less densely rooted and compacted sediment as compared to the Spartina marsh which is already present for several years. This allowed a significantly higher endofaunal species richness, abundance and biomass in the Spartina patch as compared to the Spartina marsh. Along a sequence of stages in the invasion of a hybrid Spartina, 
from tidal flat to dieback, Neira et al. (2007) observed cascading changes in sediment conditions that led to a substantial reduction in macrobenthic species richness, increased dominance and a shift in feeding modes.

Summarizing, our approach comparing two ecosystem engineering species of different strength, revealed large differences in biodiversity effects when compared to the bare mudflat. Conclusions about the mechanisms underlying these effects are hampered by the fact that these two species differ in many aspects. The use of artificial structures that mimic a single ecosystem engineering aspect would therefore be a useful tool for comparing natural species. Nevertheless, present results clearly show that (1) epibenthic vegetations of $Z$. noltii and Spatina anglica cause a shift in macrofaunal assemblages from endotowards epibenthic macrobenthic species (cf. hypothesis 3 ) and that (2) there were no clear patterns related to feeding modes (refuting hypothesis 2) and sediment properties (refuting hypothesis 1). This suggests that increased aboveground habitat complexity is probably the main mechanism driving macrobenthic biodiversity in our system, and that food availability/productivity was of lesser importance. In addition, enhanced patchiness also has a distinct positive effect on biodiversity (cf. hypothesis 4). Finally, the distinction between epibenthic and endobenthic macrofauna turned out to be very important to better understand faunal differences between engineered and non-engineered habitats.

Acknowledgments We like to acknowledge Bas Koutstaal and Jos van Soelen from the NIOO department of Spatial Ecology and all members of the Monitoring Task group at the NIOO-CEME, for their valuable support in collecting and analyzing all samples. We also greatly acknowledge Karsten Reise and two anonymous reviewers for their valuable comments that helped us to improve this manuscript. This research was part of responsive mode proposal MARENG from the EU funded network of excellence Marine Biodiversity and Ecosystem Functioning (MarBEF). This is NIOO Publication 4429 Netherlands Institute of Ecology (NIOO-KNAW).

Open Access This article is distributed under the terms of the Creative Commons Attribution Noncommercial License which permits any noncommercial use, distribution, and reproduction in any medium, provided the original author(s) and source are credited.

\section{References}

Bachelet G, de Montaudouin X, Auby I, Labourg P-J (2000) Seasonal changes in macrophyte and macrozoobenthos assemblages in three coastal lagoons under varying degrees of eutrophication. J Mar Sci 57:1494-1506

Bartholomew A (2002) Faunal colonization of artificial seagrass plots: the importance of surface area versus space size relative to body size. Estuaries 25:1045-1052

Blanchet H, De Montaudouin X, Lucas A, Chardy P (2004) Heterogeneity of macrozoobenthic assemblages within a Zostera noltii seagrass bed: diversity, abundance, biomass and structuring factors. Estuar Coast Shelf Sci 61:111-123

Bologna PAX, Heck KL Jr (2002) Impact of habitat edges on density and secondary production of seagrass-associated fauna. Estuaries 25:1033-1044

Bostrom C, Bonsdorff E (1997) Community structure and spatial variation of benthic invertebrates associated with Zostera marina (L.) beds in the north Baltic Sea. J Sea Res 37:153-166

Bouma TJ, van Duren LA, Temmerman S, Claverie T, Blanco-Garcia A, Ysebaert T, Herman PMJ (2007) Spatial patterns in flow- and sedimentation within vegetation patches: comparing field, flume and hydrodynamic modelling experiments. Cont Shelf Res 27:1020-1045

Bouma TJ, De Vries MB, Low E, Peralta G, Tanczos IC, Van de Koppel J, Herman PMJ (2005) Trade-offs related to ecosystemengineering: a case study on stiffness of emerging macrophytes. Ecology 86:2187-2199

Bowden DA, Rowden AA, Atrill MJ (2001) Effect of patch size and in-patch location on the infaunal macroinvertebrate assemblages of Zostera marina seagrass beds. J Exp Mar Biol Ecol 259:133154

Brenchley GA (1982) Mechanisms of spatial competition in marine soft-bottom communities. J Exp Mar Biol Ecol 60:17-33

Brun FG, van Zetten E, Cacabelos E, Bouma TJ (2008) Role of two contrasting ecosystem engineers (Zostera noltii and Cymodocea nodosa) on the filter feeding rate of Cerastoderma edule. Helgoland Mar Res (this issue)

Bruno JF, Stachowicz JJ, Bertness MD (2003) Inclusion of facilitation into ecological theory. Trends Ecol Evol 18:119-125

Brusati ED, Grosholz ED (2006) Native and introduced ecosystem engineers produce contrasting effects on estuarine infaunal communities. Biol Invasions 8:683-695

Castellanos EM, Figueroa ME, Davy AJ (1994) Nucleation and facilitation in saltmarsh succession: interactions between Spartina maritima and Arthrocnemum perenne. J Ecol 82:239-248

Clarke KR (1993) Non-parametric multivariate analyses of changes in community structure. Aust J Ecol 18:117-143

Corona A, Soto LA, Sanchez AJ (2000) Epibenthic amphipod abundance and predation efficiency of the pink shrimp Farfantepenaeus duorarum (Burkenroad 1939) in habitats with different physical complexity in a tropical estuarine system. J Exp Mar Biol Ecol 253:33-48

Cottet M, de Montaudouin X, Blanchet H, Lebleu P (2007) Spartina anglica eradication and in situ monitoring assess structuring strength of habitat complexity on marine macrofauna at high tidal level. Estuar Coast Shelf Sci 71:629-640

Crooks JA (2002) Characterizing ecosystem-level consequences of biological invasions: the role of ecosystem engineers. Oikos 97:153-166

Curras A, Sanchez-Mata A, Mora J (1993) Estudio comparativo de la macrofauna bentónica de un fondo de Zostera marina y un fondo arenoso libre de cubierta vegetal. Cahiers de Biologie Marine 35:91-112

Dyer FM, Thomson J, Croudace IW, Cox R, Wadsworth RA (2002) Records of change in salt marshes: a radiochronological study of three Westerschelde (SW Netherlands) marshes. Environ Sci Technol 36:854-861

Fogel BN, Crain CM, Bertness MD (2004) Community level engineering effects of Triglochin maritima (seaside arrowgrass) in a salt marsh in northern New England, USA. J Ecol 92:589-597

Fonseca MS, Cahalan JA (1992) A preliminary evaluation of wave attenuation by four species of seagrass. Estuar Coast Shelf Sci 35:565-576

Healey D, Hovel KA (2004) Seagrass bed patchiness: effects on epifaunal communities in San Diego bay, USA. J Exp Mar Biol Ecol 313:155-174 
Heck KL Jr, Orth RJ (1980) Seagrass habitats: the roles of habitat complexity, competition and predation in structuring associated fish and motile macroinvertebrate assemblages. In: Kennedy VS (ed) Estuarine perspectives. Academic Press, New York, pp 449464

Heck KL Jr, Able KW, Roman CT, Fahay MP (1995) Composition, abundance, biomass, and production of macrofauna in a New England estuary: comparisons among eelgrass meadows and other nursery habitats. Estuaries 18:379-389

Hedge P, Kriwoken LK (2000) Evidence for effects of Spartina anglica invasion on benthic macrofauna in Little Swanport estuary, Tasmania. Aust Ecol 25:150-159

Hily C, Bouteille M (1999) Modifications of the specific diversity and feeding guilds in an intertidal sediment colonized by an eelgrass meadow (Zostera marina) (Brittany, France). Comptes rendus de 1 académie des sciences série iii-sciences de la vie-life sciences 322:1121-1131

Hovel KA, Lipicius RN (2001) Habitat fragmentation in a seagrass landscape: patch size and complexity control blue crab survival. Ecology 82:1814-1829

Irlandi EA (1994) Large- and small-scale effects of habitat structure on rates of predation: how percent coverage of seagrass affects rates of predation and siphon nipping on an infaunal bivalve. Oecologia 98:176-183

Irlandi EA (1996) The effects of seagrass patch size and energy regime on growth of a suspension-feeding bivalve. J Mar Res 54:161-185

Irlandi EA, Peterson CH (1991) Modification of animal habitat by large plants: mechanisms by which seagrasses influence clam growth. Oecologia 87:307-318

Irlandi EA, Ambrose WG, Orlando BA (1995) Landscape ecology and the marine environment: how spatial configuration of seagrass habitat influences growth and survival of the bay scallop. Oikos 72:307-313

Jones CG, Lawton JH, Shachak M (1994) Organisms as ecosystem engineers. Oikos 69:373-386

Jones CG, Lawton JH, Shachak M (1997) Positive and negative effects of organisms as physical ecosystem engineers. Ecology 78:1946-1957

Jouquet P, Boulain N, Gignoux J, Lepage M (2004) Association between subterranean termites and grasses in a West African savanna: spatial pattern analysis shows a significant role for Odontotermes n. pauperans. Appl Soil Ecol 27:99-107

Kneib RT (1984) Patterns of invertebrate distribution and abundance in the intertidal salt-marsh-causes and questions. Estuaries $7: 392-412$

Lacambra C, Cutts N, Allen J, Burd F, Elliott M (2004) Spartina anglica: a review of its status, dynamics and management. English nature research reports, no. 527. Institute of Estuarine and Coastal Studies, University of Hull

Leonard LA, Wren PA, Beavers RL (2002) Flow dynamics and sedimentation in Spartina alterniflora and Phragmites australis marshes of the Chesapeake Bay. Wetlands 22:415-424

Levin LA, Talley TS (2000) Influences of vegetation and abiotic environmental factors on salt marshes invertebrates. In: Weinstein MP, Kreeger DA (eds) Concepts and controversies in tidal marsh ecology. Kluwer, Dordrecht, pp 661-707

Levin LA, Neira C, Grosholz ED (2006) Invasive cordgrass modifies wetland trophic function. Ecology 87:419-432

Mc Corry MJ, Otte ML (2000) Ecological effects of Spartina anglica on the macro-invertebrate infauna of the mud flats at Bull Islands, Dublin bay, Ireland. Web Ecol 2:71-73

Moseman SM, Levin LA, Currin C, Forder C (2004) Colonization, succession, and nutrition of macrobenthic assemblages in a restored wetland at Tijuana Estuary, California. Estuar Coast Shelf Sci 60:755-770
Neira C, Levin LA, Grosholz ED (2005) Benthic macrofaunal communities of three sites in San Francisco Bay invaded by hybrid Spartina, with comparison to uninvaded habitats. Mar Ecol Prog Ser 292:111-126

Neira C, Grosholz ED, Levin LA, Blake R (2006) Mechanisms generating modification of benthos following tidal flat invasion by a Spartina hybrid. Ecol Appl 16:1391-1404

Neira C, Levin LA, Grosholz ED, Mendoza G (2007) Influence of invasive Spartina growth stages on associated macrofaunal communities. Biol Invasions 9:975-993

Netto SA, Lana PC (1997) Intertidal zonation of benthic macrofauna in a subtropical salt mars hand nearby unvegetated flat (SE, Brazil). Hydrobiologia 353:171-180

Netto SA, Lana PC (1999) The role of above- and below-ground components of Spartina alterniflora (Loisel) and detritus biomass in structuring macrobenthic associations of Paranagua Bay (SE Brazil). Hydrobiologia 400:167-177

Norkko A, Hewitt JE, Thrush SF, Funnell GA (2006) Conditional outcomes of facilitation by a habitat-modifying subtidal bivalve. Ecology 87:226-234

Orth RJ (1992) A perspective on plant-animal interaction in seagrasses: physical and biological determinants influencing plant and animal abundance. In: John DM, Hawkins SJ, Price JH (eds) Plant-animal interactions in the marine benthos. Clarendon Press, Oxford, pp 147-164

Orth RJ, Heck KL, Van Montfrans J (1984) Faunal communities in seagrass beds-a review of the influence of plant structure and prey characteristics on predator prey relationships. Estuaries $7: 339-350$

Peralta G, Morris EP, van Duren LA, Bouma TJ (2008) Consequences of shoot density and stiffness for ecosystem engineering by benthic macrophytes in flow dominated areas: a hydrodynamic flume study. Mar Ecol Prog Ser 368:103-115

Rader DN (1984) Salt-marsh benthic invertebrates: small-scale patterns of distribution and abundance. Estuaries 7:413-420

Reichman OJ, Seabloom EW (2002) The role of pocket gophers as subterranean ecosystem engineers. Trends Ecol Evol 17:44-49

Ringold P (1979) Burrowing, root mat density, and the distribution of fiddler crabs in the eastern United States. J Exp Mar Biol Ecol 36:11-21

Seitz RD, Lipicius RN, Seebo MS (2005) Food availability and growth of the blue crab in seagrass and unvegetated nurseries of Chesapeake Bay. J Exp Mar Biol Ecol 319:57-68

Stoner AW (1980) The role of seagrass biomass in the organization of benthic macrofaunal assemblages. Bull Mar Sci 30:537-551

van Hulzen JB, Van Soelen J, Bouma TJ (2007) Morphological variation and habitat modification are strongly correlated for the autogenic ecosystem engineers Spartina anglica (common cordgrass). Estuar Coasts 30:3-11

van Wesenbeeck BK, van de Koppel J, Herman PMJ, Bakker JP, Bouma TJ (2007) Biomechanical warfare in ecology; negative interactions between species by habitat modification. Oikos 116:742-750

Wang Q, An SQ, Ma ZJ, Zhao B, Chen JK, Li B (2006) Invasive Spartina alterniflora: biology, ecology and management. Acta Phytotaxon Sin 44:559-588

Whaley SD, Minello TJ (2002) The distribution of benthic infauna of a Texas salt marsh in relation to the marsh edge. Wetlands 22:753-766

Webster PJ, Rowden AA, Atrill MJ (1998) Effect of shoot density on the infaunal macro-invertebrate community within a Zostera marina seagrass bed. Estuar Coast Shelf Sci 47:351-357

Whitcraft CR, Levin LA (2007) Regulation of benthic algal and animal communities by salt marsh plants: impact of shading. Ecology 88:904-917 
Widdows J, Brinsley M (2002) Impact of biotic and abiotic processes on sediment dynamics and the consequences tot the structure and functioning of the intertidal zone. J Sea Res 48:143-156

Wright JP, Jones CG (2004) Predicting effects of ecosystem engineers on patch-scale species richness from primary productivity. Ecology 85:2071-2081

Wright JP, Jones CG (2006) The concept of organisms as ecosystem engineers ten years on: Progress, limitations, and challenges. BioScience 56:203-209
Yang SL (1998) The role of Scirpus marsh in attenuation of hydrodynamics and retention of fine-grained sediment in the Yangtze Estuary. Estuar Coast Shelf Sci 47:227-233

Ysebaert T, Herman PMJ, Meire P, Craeymeersch J, Verbeek H, Heip CHR (2003) Large-scale spatial patterns in estuaries: estuarine macrobenthic communities in the Schelde estuary, NW-Europe. Estuar Coast Shelf Sci 57:335-355 